\title{
The effects of ultrasonic irradiation in combination with ozone on the reduction of residual ethion of tangerine (Citrus reticulata Blanco cv. Sai Nam Pung) fruit after harvest
}

\author{
Kanda Whangchai ${ }^{1,2,3^{*}}$, Satit Phiyanalinmat ${ }^{4}$, Jamnong Uthaibutra $^{1,2,3}$, Sarunya Pengphol ${ }^{5}$, \\ Nakao Nomura ${ }^{6}$ \\ ${ }^{1}$ Postharvest Technology Innovation Center, Commission on Higher Education, Bangkok, Thailand; \\ *Corresponding Author: kanda.w@cmu.ac.th \\ ${ }^{2}$ Postharvest Technology Research Institute, Chiang Mai University, Chiang Mai, Thailand \\ ${ }^{3}$ Postharvest Technology Research Institute, Chiang Mai University, Chiang Mai,Thailand \\ ${ }^{4}$ Department of Industrial Chemistry, Faculty of Science, Chiang Mai University, Chiang Mai, Thailand \\ ${ }^{5}$ Faculty of Agriculture and Industrial Technology,Nakonsawan Rajabhat University, Nakonsawan, Thailand \\ ${ }^{6}$ Graduate School of Life and Environmental Science, University of Tsukuba, 1-1-1 Tennodai, Tsukuba, lbaraki, Japan
}

Received 2013

\section{ABSTRACT}

Ethion residue removal efficiency using individual and combined effects of ultrasonication (US), ozonation $\left(\mathrm{O}_{3}\right)$, ultrasonication and ozonation $\left(\mathrm{US} / \mathrm{O}_{3}\right)$ was investigated. A $1 \mathrm{mg} \cdot \mathrm{L}^{-1} \mathrm{stan}$ dard ethion was subjected to an ultrasonic irradiation (3W input power) device with different frequencies of $108,400,700,1000 \mathrm{kHz}$, and to an ozone with a concentration of $200 \mathrm{mg} \cdot \mathrm{mL}^{-1}$ with various exposure times $(0,15,30,45$ and 60 minutes). Reduction of residual ethion was determined by gas chromatography with flame photometric detection (GC-FPD). It was found that $1000 \mathrm{kHz}$ ultrasonic irradiation for $60 \mathrm{~min}$ utes was the most effective treatment for reducing ethion concentration. Additionally, ozone could reduce the concentration of standard ethion after 60 minutes of exposure. Ultrasonic irradiation in combination with ozone had a synergistic effect in reducing standard ethion concentration, with the highest rate occurring within the first 15 minutes. Ethion concentration was reduced to $75.43 \%$ after ultrasonic irradiation at $1000 \mathrm{kHz}$ and ozone exposure for $60 \mathrm{~min}$ utes. The effectiveness of the combined scheme for reducing of ethion residues on tangerine was also determined by GC-FPD. The ethion residue on fresh tangerines after ultrasonic irradiation and ozone washing was reduced by $73.03 \%$ after 60 minutes. The present study demonstrates that ultrasonic irradiation and ozone exposure could be used to reduce ethion residues in treated tangerine in order to meet the Standards for Pesticide Residue Limits.

Keywords: Tangerine; Ethion; Pesticide Residue; Ozone; Ultrasonic Irradiation

\section{INTRODUCTION}

The economical important pests in tangerine production are Asian citrus psyllid (Diaphorina citri Kuwayama: Psyllidae) the carrier of citrus greening disease (greening), citrus aphid (Toxoptera sp.), chilli thrips (Scirtothrips dorsalis Hood: Thripidae), and the African red mite (Eutetranychus africanus Tucker: Tetranychidae). The pest feed on tangerine fruits and spread diseases which in turn ruin the fruits' appearance. To prevent these growers, they have to apply a lot of chemical pesticides every week, even at the harvesting time to improve the tangerines' aesthetic quality.

There were several batches of tangerine in one plant at a time reported by Davis and Albrigo (1994) [1]. Therefore, in one batch, the chemical pesticides applied to the tangerines, it would unavoidably affect other batches, and led to the chemical residue problems. The insecticides used for controlling thrips were ethion, abamectin, imidacloprid, methomyl, and carbosulfan, respectively.

Ethion is an organophosphate pesticide for controlling aphids, mites, and thrips. It inhibits the cholinesterase enzyme in an insect's nervous system. Currently, growers widely use ethion, which leaves the chemical residues on the surface of fruits and vegetables, and sometimes 
absorbs into the plant tissues. It has been reported that tangerines consisted of ethion concentrations above the Maximum Residue Limits (MRL) level $\left(1.0 \mathrm{mg} \cdot \mathrm{kg}^{-1}\right)$, and $31.8 \%$ of the sampled fruits were contaminated with ethion, cypermethrin, profenophos, carbaryl, chlopyrifos, and carbosulfan residue below the tangerine MRL level. They analyzed the peel and flesh of 50 tangerine fruits collected from the growers, local market and super market in Chiang Mai, Lamphun, and Lampang from November 2008 to December 2009. They found that pesticide residue content, i.e. ethion, profenofos, and triazofos were higher than the MRL level. An average ethion concentration of $1.14 \mathrm{mg} \cdot \mathrm{kg}^{-1}$, it was found in $92 \%$ of the peel samples. Moreover, $50 \%$ of tangerine flesh samples were found to contain an average concentration of 0.01 $\mathrm{mg} \cdot \mathrm{kg}^{-1}$ ethion [2].

Ultrasonic irradiation technology effectively reduces a variety of organic and inorganic contaminants and its acoustic cavitations generate many hot spots with high temperatures and pressures those cause the sonolysis of $\mathrm{H}_{2} \mathrm{O}$ molecules. Consequently, radical species $\mathrm{H},{ }^{\bullet} \mathrm{OH}$, - $\mathrm{OOH}$ are formed which lead to a direct destruction of chemicals in aqueous solution [3]. Hoffman et al.(1996) reported that ultrasonication at the frequency of 20 to $500 \mathrm{kHz}$ was the effective method in the rapid destruction of organic contaminants in water [4]. In addition, Wang et al. (2000) indicated that methyl parathion could be degraded using ultrasonication at a frequency of 40 $\mathrm{kHz}$ [5]. While Song et al. (2007) reported that ultrasonication at $200 \mathrm{kHz}$ for 240 seconds effectively to sink Microcystis surface scum and could be used to reduce mycrocystin toxin and musty odor substances in aquaculture pounds [6]. There was no report on the treatment with ultrasonication and ozonation especially on tangerine.

Ozonation is a promising method to reduce chlopyrifos in the pericarp and aril of fresh lychee [7]. Furthermore, Inan et al.(2007) reported the reduction of aflatoxin $\mathrm{B}_{1}$ content in flaked and chopped red peppers (Capsicum annuum) by 80 and $93 \%$ at the rate of 33 and $66 \mathrm{mg} \cdot \mathrm{L}^{-1}$, respectively after 6 hours of ozone exposure [8]. Wu et al. (2007) demonstrated that using dissolved ozone (1.4 $\mathrm{mg} \cdot \mathrm{L}^{-1}$ ) for 60 minutes was the effective method to reduce $60 \%$ - $99 \%$ of methyl-parathion, cypermethrin, parathion and diazinon in aqueous solution [9]. This research mainly studied the effectiveness of ultrasonic irradiation and ozone on the reduction of standard ethion and residual ethion on tangerine.

\section{MATERIAL AND METHODS}

Ethion standard was purchased from Sigma-Aldrich Laborchemikalien GmbH (Stienheim, Germany) with a 99.9\% purity (ethion structure is shown in Figure 1). Ethion stock solution $\left(1000 \mathrm{mg} \cdot \mathrm{L}^{-1}\right)$ was prepared for the pesticide residue analysis using acetone as the solvent for high-performance liquid chromatography (HPLC) grade 99.9\%, from RCI Labscan Ltd. (Bangkok, Thailand). The solution was diluted with deionized distilled water to the appropriate concentrations.

Ultrasonic devices, with an input power of 3 watts and 4 varying frequencies; $108,400,700,1000 \mathrm{kHz}$ and made by Honda Electronics Company (Toyohashi, Aichi, Japan), were utilized for three replications. A polyethylene cylinder reactor $10 \mathrm{~cm}$ in diameter, equipped with a transducer at the lower part was used. Standard ethion $(25 \mathrm{~mL})$ or KI solution in a flask was sonicated in an ultrasonic reactor.

Ozone gas produced by an ozone generator (Ozonizer, Sky zone model S05AE) was bubbled into ethion solution in a flask. The ozone gas was bubbled with a flow rate of $25 \mathrm{ml} \cdot \mathrm{min}^{-1}$. Dissolved ozone was determined by the indigo colorimetric method [11].

The treatments that shown good results in ethion degradation from above experiment was used for combination of ultrasonication and ozone treatment. The ethion standard was prepared in the ultrasonic reactor mention ealier. The solution was bubbled with ozone gas from ozone generator. Samples were collected for the determination of ethion concentration using GC-FPD (Agilent Technologies Model 6890) and percentage of removal rate of the ethion were calculated as the degradation percentage.

\subsection{Study of Optimum Frequency of Ultrasonic Irradiation and Ozone Treatment for Liberation of lodine and Reducing Standard Ethion Solution at Different Times}

Standard ethion concentration of $1 \mathrm{mg} \cdot \mathrm{L}^{-1}$ or $2 \% \mathrm{KI}$ solution was prepared in a flask and then placed inside the ultrasonic reactor mentioned earlier and subjected to different frequencies at 108, 400, 700, and $1000 \mathrm{kHz}$. A $200 \mathrm{mg} \cdot \mathrm{L}^{-1}$ ozone gas was bubbled for $15,30,45$ and 60 minutes through the ethion solution or KI. The concentration of iodine liberation from $2 \%$ potassium iodine with different times, was measured at $354 \mathrm{~nm}$ using spectrophotometer. Finally, three replicates of ethion samples were analyzed by a gas chromatograph equipped with a flame photometric detector (GC-FPD). Then, the

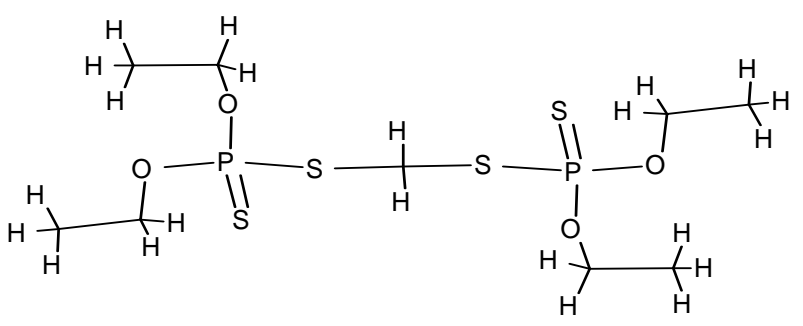

Figure 1. The chemical structure of ethion [10]. 
percent removal of the ethion was calculated at each collection time to compare the best method.

\subsection{Reduction of Ethion on Harvested Tangerine using Ultrasonic Irradiation and Ozone}

An ultrasonic device volume $55 \mathrm{~L}$ equipped with eight transducers and ultrasonic frequency at $1000 \mathrm{kHz} 24 \mathrm{~W}$ was used in large-scale application. The ultrasonic device was also made by Honda Electronics Company (Toyohashi, Aichi, Japan). Tangerine samples were treated with ethion 1 day before harvesting. The fruits were immersed in distilled water and subjected to washing using ultrasonic reactor, ozone and their combination while washing using only distilled water was employed as the control. The $5 \mathrm{~g}$ of chopped tangerine was extracted with acetone and methylene chloride homogenized at 13,000 rpm for 1 minute and dried using rotary vacuum evaporation at 340 mbar [12]. The final solvent was HPLC grade of acetone. Then the samples were analyzed ethion residue using GC-FPD as previous report [13].

\subsection{GC-FPD Instrument and Conditions}

The GC-FPD analysis was performed with an Agilent Technologies (Wilmington, DE) model 6890 gas chromatograph equipped with a flame photometric detector. The GC was carried out using a fused silica capillary column HP-5, 5\% Phenyl Methyl Siloxane, with dimensions of $30 \mathrm{~m} \times 0.32 \mathrm{~mm}$ i.d. and a $0.25 \mu \mathrm{m}$ film thickness (Agilent Technologies). The temperature was programmed at $10^{\circ} \mathrm{C} \cdot \mathrm{min}^{-1}$ from the initial temperature at $100^{\circ} \mathrm{C}$ to $200^{\circ} \mathrm{C}$. And then at $4^{\circ} \mathrm{C} \cdot \mathrm{min}^{-1}$, it increased to the final temperature of $220^{\circ} \mathrm{C}$. A purified He carrier gas was used with the flow rate of $3.6 \mathrm{~mL} \cdot \mathrm{min}^{-1}$. The detector temperature was set at $250^{\circ} \mathrm{C}$. Those sample solutions $(1.0 \mu \mathrm{L})$ were injected in splitless mode, and the quantification of ethion was performed using ethion standard as a reference.

\subsection{Statistical Analysis}

All experiments were replicated three times and evaluated with a regression procedure using the SPSS version 17. Duncan's Multiple Range Test $\left({ }^{*} P \leq 0.05\right)$ was performed to determine the significant difference among various treatments.

\section{RESULTS AND DISCUSSION}

\subsection{Study of Optimum Frequency and Time for lodine Liberation and Reducing Standard Ethion Solution by Ultrasonic Irradiation and Ozone Treatment}

Iodine production was a direct measurement of soni- cation and ozonation effects. Iodine yield increased with increasing ultrasonic frequencies directly and it reached the highest value of iodine production rate (absorbance of OD 354) when ultrasonic frequency was $1000 \mathrm{kHz}$ with ozone exposure for 60 minutes (Figure 2) These results indicated that ultrasonic irradiation generated highly active hydroxyl radicals, which reacted with potassium iodide to release iodine in the process [14].

The effectiveness of ultrasonic irradiation to reduce the concentration of standard ethion solution $\left(1 \mathrm{mg} \cdot \mathrm{L}^{-1}\right)$ was also investigated. It was found that the ethion concentration was significantly reduced with prolonged ultrasonic exposure time. Moreover, ultrasonic irradiation at $1000 \mathrm{kHz}$ for 60 minutes was the most effective treatment for reducing ethion concentration (Figure 3 ). The advantage effect of high ultrasonic frequency may be due to the increasing cavitational activity which led to a higher number of collapsing cavities directly influencing

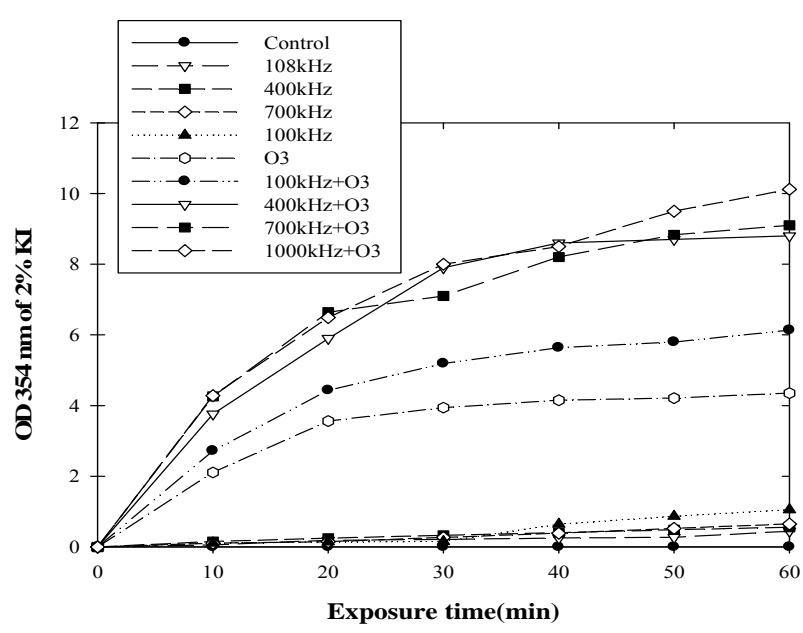

Figure 2. Changes of KI absorbance at $354 \mathrm{~nm}$ after exposed to ultrasonic irradiation and ozone treatment.

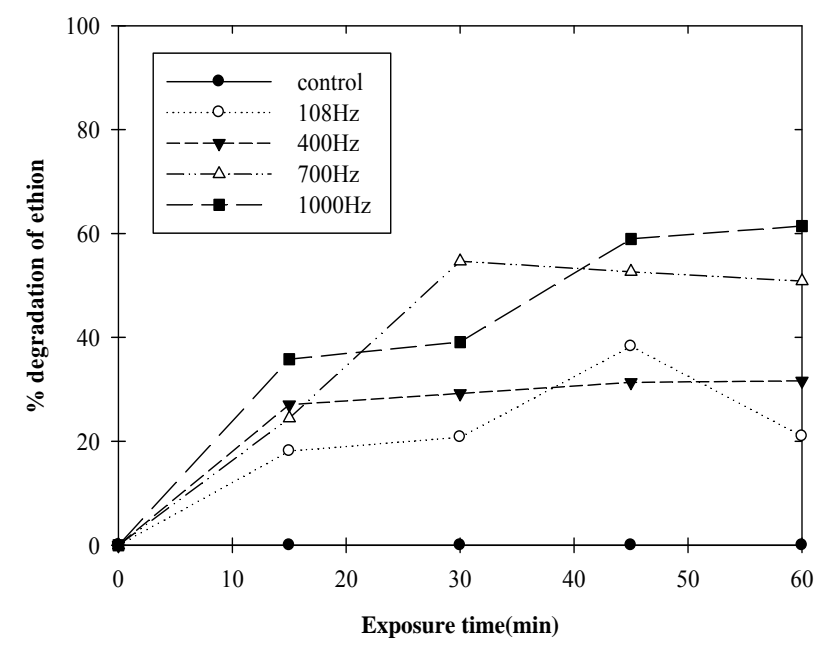

Figure 3. Percent removal of ethion standard solution using ultrasonic irradiation with various frequencies. 
relevant report of Yao et al.(2010) that the optimal fre the reduction rate of ethion. This evidence followed the quency for parathion degradation occurred at $600 \mathrm{kHz}$ and it attributed to the much higher ${ }^{\circ} \mathrm{OH}$ yield compared to treatments at $200 \mathrm{kHz}[15]$.

Similar results obtained for the ozone-treated standard solution of ethion. Reduction of ethion concentration was directly proportional to increase in ozone exposure time. At 60 minutes exposure, ethion concentration decreased by $66.85 \%$ (Figure 4). Ozone is a strong oxidant and it could possibly degrade the ethion. As reported by $\mathrm{Ku}$ et al. (1998) the diazinon degradation occurred within 1 hour of ozone treatment [16]. These results agreed well with the previous studies on the reduction of carbamate pesticides and some organic phosphorus in water solution after ozone treatment with the same range of contact times [17].

The ethion solution treated with ultrasonication in combination with ozone (US/ $\mathrm{O}_{3}$ ) showed the improved rate of ethion degradation, with the highest degradation rate took place after the first 15 minutes. This may be due to the synergistic effect of ultrasonic-ozone treatment, degraded and oxidized ethion structure. Moreover, the combination $\left(\mathrm{US} / \mathrm{O}_{3}\right)$ scheme for 60 minutes with 1000 $\mathrm{kHz}$ US, its exposure time reduced the ethion concentration by $75.43 \%$, which is significantly $\left({ }^{*} P<0.05\right)$ higher compared with other treatments (Figure 4). Therefore, ultrasonication and ozonation in combination exhibited a promising treatment for residual ethion removal that accomplished by ozone or ultrasonication alone. Thus, there was a synergistic effect to use ultrasonic and ozone treatments together. This followed the similar findings by Weaver et al. (1998) who reported the importance of the rapid degradation of organic contaminants using ozone and ultrasonic irradiation $(20 \mathrm{kHz})$ resulting in an increase of hydroxyl radicals[3].

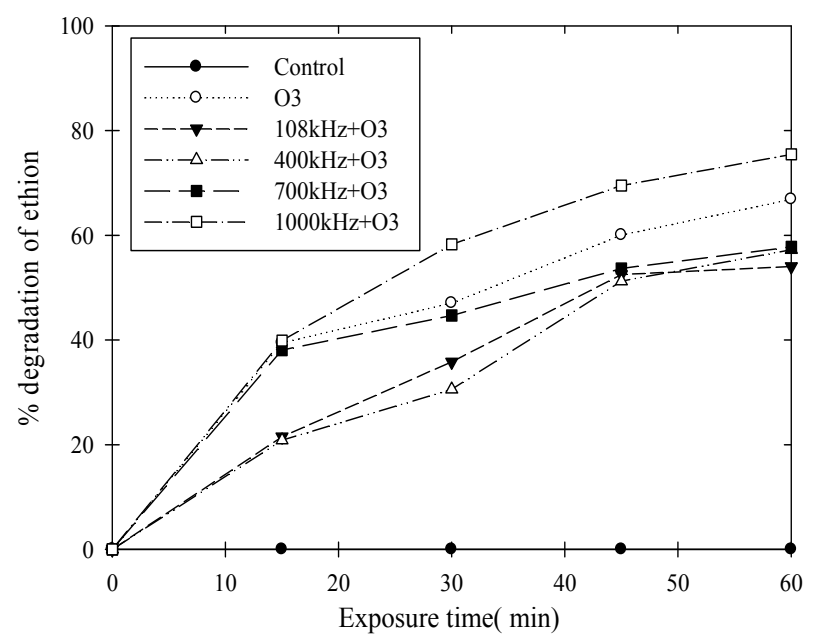

Figure 4. Percent removal of ethion standard solution using the combinations of ultrasonic irradiation and ozone treatment.

\subsection{Reduction of Ethion on Harvested Tangerine Using Ultrasonic Irradiation and Ozone}

Tangerine fruits were immersed in an ultrasonic reactor with the frequency of $1000 \mathrm{kHz}$ and combined with ozone treatment in order to reduce residual ethion. It was found that the ethion residue on fresh tangerine showed the lowest level $(0.03 \mathrm{ppm})$ or $73.07 \%$ of removal rate when the ultrasonic frequency was $1000 \mathrm{kHz}$ and combined with the ozone treatment for 60 minutes with significant $\left({ }^{*} P<0.05\right)$ different when compared with an individual treatment and the control, which was immersed in distilled water (Figure 5). This tendency could be explained by the reaction of ultrasonic frequencies with exposure ozone producing the ${ }^{\bullet} \mathrm{OH}$ radical, which effectively decomposed ethion residue on the tangerine surface. Similarly, Wenrong et al. (2002) reported that the decomposition rate of arsenazo treated by ozone or ultrasonic was more rapid than that treated by ozone alone and the structure of arsenazo was decomposed more completely[18]. In addition, Wu et al.(2007) also indicated that ozone water treatment could effectively reduce pesticides (methyl-parathion, parathion, diazinon and cypermethrin) residue on Pak Choi (Brassica rapa) surface [9].

\section{CONCLUSIONS}

The concentration of ethion was reduced after using ultrasonic or ozone treatment. The reduction could increase with increasing contact time directly. The higher the ultrasonic frequencies, the greater the percent removal could achieve. The combined ultrasonic and ozone treatments had a synergistic effect on ethion degradation

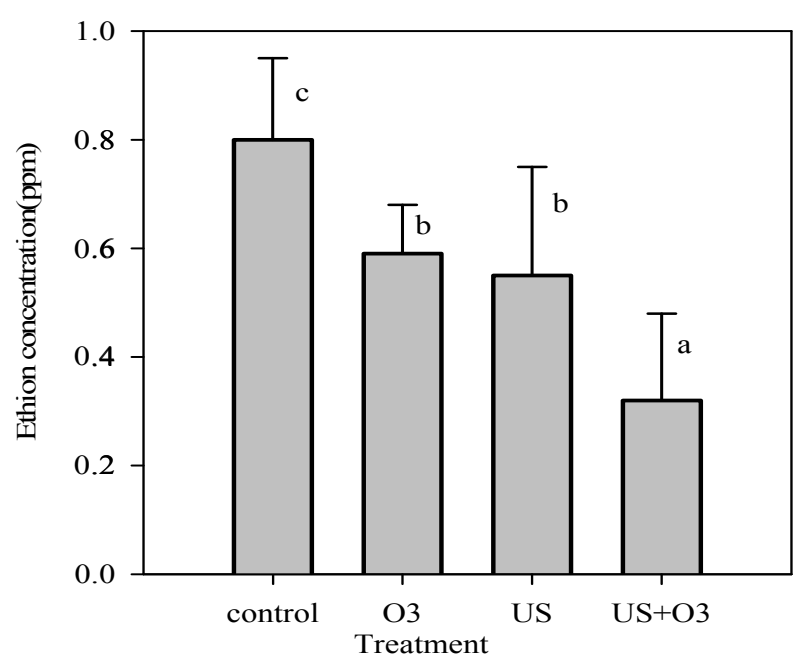

Figure 5. Ethion residue in tangerine after washing in the combination of ultrasonication and ozonation. Error bars denote standard deviations. Different letters indicate significant differences by Duncan's multiple range test $(p \leq 0.05)$. 
in both aqueous solution and ethion treated tangerines. Therefore, further studies to reduce the toxicity of pesticides contaminated agricultural products are also required.

\section{ACKNOWLEDGEMENTS}

This research was supported by the Postharvest Technology Innovation Center, Commission on Higher Education, Bangkok. The authors are also grateful to the Faculty of Science and Postharvest Technology Research Institute, Chiang Mai University, Thailand for providing the laboratory facilities and to Honda Electronics Company Toyohashi, Aichi, Japan for ultrasonic device support.

\section{REFERENCES}

[1] Davis, F. S. and Albrigo, L. G. (1994) Citrus. CAB Interntioal, Walling, Oxon, U.K., p.254.

[2] Wongkaew, L. (2009) Survey of the use of pesticides in tangerine in Chiang Mai province Thailand. Annual report of Department of Agriculture.

http://it.doa.go.th/pibai/pibai/n13/v-6-july/jakfarm.html

[3] Weavers, L.K., Ling, F.H. and Hoffmann, M.R. (1998) Aromatic compound degradation in water using a combination of sonolysis and ozonolysis. Environmental Science \& Technolology,32, 2727-2733. doi:10.1021/es970675a

[4] Hoffmann, M.R, Hua, I. and HÖchemer, R. (1996) Application of ultrasonic irradiation for the degradation of chemical contaminants in water. Ultra sonics Sonochemistry, 3, S163-S172. doi:10.1016/s1350-4177(96)00022-3

[5] Wang, J., Pan, Z., Zhang, Z., Zhang, X., Wen, F., Ma, T., Jiang, Y., Wang, L., Xu, L. and Kang, P. ( 2006) Sonocatalytic degradation of methyl parathion in the cvpresence of nanometer and ordinary anatase titanium dioxide catalysts and comparison of their sonocatalytic abilities. Ultrasonics Sonochemistry, 13, 493-500. doi:10.1016/j.ultsonch.2005.11.002

[6] Song, W. and O'Shea, K.E. (2007) Ultrasonically induced degradation of 2-methylisoborneol and geosmin. Water Research, 41, 2672-2678.

[7] Whangchai, K., Uthaibutra, J., Phiyanalinmat, S., Pengphol, S. and Nomura,N. (2011) Effect of ozone treatment on the reduction of chlorpyrifos residues in fresh lychee fruits. Ozone Science and Engineering, 33, 232-236. doi: 10.1080/01919512.2011.554313

[8] Inan, F., Pala, M. and Doymaz, I.( 2007) Use of ozone in detoxification of aflatoxin $\mathrm{B}_{1}$ in red pepper. Journal of Stored Product Research, 43, 425-429. doi:10.1016/j.jspr.2006.11.004

[9] Wu, J., Luan, T., Lan, C., Lo, T. W.H. and Chan, G. Y. S. (2007) Removal of residual pesticides on vegetable using ozonated water. Food Control, 18, 466-472. doi:10.1016/j.foodcont.2005.12.011

[10] Ethion.[Online].Available: http://toxipedia.org/display/toxi pedia/Ethion (January 19, 2011).

[11] Eaton, A.D., Clesceri, L.S., Rice, E.W., Greenberg, A. E. (2005) Standard Methods for the Examination of Water and Waste-Water $21^{\text {th }}$ ed. Am. J. Public Health. Washington DC, USA.

[12] Fenoll, J., P., Hellín, C.M., Martínez, Miguel, M. and Flores, P. (2007) Multiresidue method for analysis of pesticides in pepper and tomato by gas chromatography with nitrogen- phosphorus detection. Food Chemistry, 105, 711-719. doi:10.1016/j.foodchem.2006.12.060

[13] Pengpol,S.,Uthaibutra,J., Arquero, O. A., Nomura,N. (2011) Reduction of residual Chlorpyrifos on harvested bird chillies (Capsicum frutescens) using ultrasonication and ozonation. Thai Journal of Agri cultural Science, 44, 182-187.

[14] Hart, E.J. and Henglein, A. (1985) Free radical and free atom reactions in the sonolysis of aqueous iodide and formate solutions. Journal of Physic Chemistry, 89, 43424347. doi:10.1021/j100266a038

[15] Yao, J-J., Gao, N-Y., Li, C. and Xu, B. (2010) Mechanism and kinetics of parathion degradation under ultrasonic irradiation. Journal of Hazardous Materials, 175, 138-145. doi:10.1016/j.jhazmat.2009.09.140

[16] Ku, Y., Chang, J.L., Shen, Y.S. and Lin, S.Y. (1998) Decomposition of diazinon in aqueous solution by ozonation. Water Research, 32, 1957-1963. doi:10.1016/s0043-1354(97)00353-9

[17] Faust, S.D. and Gomma, H.M. (1972) Chemical hydrolysis of some organic phosphorus and carbamate pesticides in aquatic environment. Environmental Letters, 3, 171201. doi:10.1080/00139307209435465

[18] Wenrong, H. and Haiyan, P. (2002) Decomposed characteristic of azo dyes by ozonization with ultrasonic enhancement. E-Journal of Chinese Science Bulletin, 47, 986-989. 